\title{
Age-dependent effects of microglial inhibition in vivo on Alzheimer's disease neuropathology using bioactive-conjugated iron oxide nanoparticles
}

\author{
Micaela Glat ${ }^{1 \dagger}$, Hadas Skaat ${ }^{2+}$, Noa Menkes-Caspi ${ }^{1}$, Shlomo Margel ${ }^{2}$ and Edward A Stern ${ }^{1,3^{*}}$
}

\begin{abstract}
Background: Tau dysfunction is believed to be the primary cause of neurodegenerative disorders referred to as tauopathies, including Alzheimer's disease, Pick's disease, frontotemporal dementia and Parkinsonism. The role of microglial cells in the pathogenesis of tauopathies is still unclear. The activation of microglial cells has been correlated with neuroprotective effects through the release of neurotrophic factors and through clearance of cell debris and phagocytosis of cells with intracellular inclusions. In contrast, microglial activation has also been linked with chronic neuroinflammation contributing to the development of neurodegenerative diseases such as tauopathies. Microglial activation has been recently reported to precede tangle formation and the attenuation of tau pathology occurs after immunosuppression of transgenic mice.
\end{abstract}

Methods: Here we report the specific inhibition of microglial cells in rTg4510 tau-mutant mice by using fibrin $\gamma^{377-395}$ peptide conjugated to iron oxide $\left(\gamma-\mathrm{Fe}_{2} \mathrm{O}_{3}\right)$ nanoparticles of $21 \pm 3.5 \mathrm{~nm}$ diameter.

Results: Stabilization of the peptide by its covalent conjugation to the $\gamma-\mathrm{Fe}_{2} \mathrm{O}_{3}$ nanoparticles significantly decreased the number of the microglial cells compared to the same concentration of the free peptide. The specific microglial inhibition induces different effects on tau pathology in an age dependent manner. The reduction of activation of microglial cells at an early age increases the number of neurons with hyperphosphorylated tau in transgenic mice. In contrast, reduction of activation of microglial cells reduced the severity of the tau pathology in older mice. The number of neurons with hyperphosphorylated tau and the number of neurons with tangles are reduced than those in animals not receiving the fibrin $\gamma^{377-395}$ peptide-nanoparticle conjugate.

Conclusions: These results demonstrate a differential effect of microglial activity on tau pathology using the fibrin $\gamma^{377-395}$ peptide-nanoparticle conjugate, depending on age and/or stage of the neuropathological accumulation and aggregation.

Keywords: Tau, Microglia, Tangle, Fibrin $\gamma^{377-395}$ peptide, Iron oxide nanoparticles

\footnotetext{
* Correspondence: sterned@mail.biu.ac.il

${ }^{\dagger}$ Equal contributors

${ }^{1}$ Gonda Multidisciplinary Brain Research Center, Bar-llan University,

Ramat-Gan 52900, Israel

${ }^{3}$ MassGeneral Institute of Neurodegenerative Disease, Massachusetts Genral

Hospital and Harvard Medical School, Charlestown, MA 02129, USA

Full list of author information is available at the end of the article
} 


\section{Introduction}

Tau protein is present in phosphorylated and aggregated form in Alzheimer's disease (AD) and in a group of neurodegenerative disorders collectively termed tauopathies [1].

Tau is a microtubule-associated protein (MAP) that under normal physiological conditions is involved in microtubule assembly and stabilization [2,3]. In the normal adult human brain, six isoforms of tau are produced from a single gene by alternative mRNA splicing in exons 2,3 , and 10 of the tau gene located on chromosome $17[4,5]$. Tau occurs mainly in axons, whereas another MAP protein, MAP2, is localized to the somatodendritic compartment [6].

Tauopathies are characterized by an abnormal hyperphosphorylation of the tau protein in sites not normally phosphorylated and later assembled into neurofibrillary tangles (NFTs) in neuronal cell bodies and sometimes in glial cells [7]. Early hyperphosphorylation is facilitated by kinases such as glycogen synthase kinase 3 (GSK3), cyclindependent kinase 5 (cdk5) and c-Jun N-terminal kinase (JNK) $[8,9]$. Hyperphosphorylation and the formation of NFTs create conditions in which the tau protein is unable to bind with microtubules, producing impairments in axonal trafficking and profound effects on the function and viability of neurons, contributing to synaptic dysfunction and neurodegeneration [10-12].

Microglial cells are the resident immune cells of the CNS $[13,14]$. Under physiological conditions, residential microglial cells are quiescent and scattered throughout the CNS [15], and are characterized by a small cell body and a ramified morphology. Occasionally, microglia will become moderately activated in order to play the classic role as "scavengers" for the maintenance and restoration of the CNS. They begin to proliferate, changing their morphology into an amoeboid shape and phagocytose cells that are pathologically damaged or developmentally unnecessary [16]. These functions of microglia are controlled by communication with cytokines, chemokines, trophic factors, and other neuromodulating molecules among neurons, astrocytes and microglia [17].

Several studies have shown that microglial cells are beneficial for the proper function of the CNS through phagocytosis of cell debris [18-20]. It has been suggested that this phagocytic activity plays a fundamental role in facilitating reorganization of neuronal circuits and triggering repair in neurodegenerative diseases. Furthermore, it was shown that insufficient clearance by microglia, prevalent in tau pathology and declining with age, is associated with an inadequate regenerative response [21]. Activated microglial cells have also been reported to possess neuroprotective/ neurotrophic effects in vitro [22]. Activated microglia could secrete some neurotrophic factors such as NGF, NT-3 and BDNF which have been demonstrated to be neuroprotective [23]. However, other studies have shown that inflammation plays a key role in the progression of neurodegenerative diseases such as AD. In an animal model of tauopathies, early microglial activation was associated with loss of synapses preceding tangle formation, suggesting that microglial activation is a cause of neuronal degeneration rather than a consequence of it [24-26]. Therefore, controversy exists about the role microglial function plays in the development of the progression of neurodegenerative diseases, driving the need for a more precise method of testing microglial function. To do so, we have utilized a specific inhibitor of microglial cells, the fibrinogen-derived $\gamma^{377-395}$ peptide, for the inhibition of microglial cells at various stages of the tauopathy disease.

The fibrinogen-derived $\gamma^{377-395}$ peptide has been recently reported as a specific inhibitor of microglial activation via the MAC-1 receptor $\left(\alpha_{M} \beta_{2}, C D 11 b / C D 18\right)$ $[27,28]$. The main disadvantage of fibrin $\gamma^{377-395}$ peptide is its short in vivo half-life time due to rapid enzymatic degradation, leading to loss of biological activity and functions. It requires, therefore, frequent direct injections of the peptide in order to maintain its bioavailability necessary for microglia inactivation. However, repeated direct intracranial administration may lead to undesirable systematic effects and toxicity. To obtain a steady administration over-time, peptides are adsorbed onto, or encapsulated within, nano-materials to protect their stability and biological activity in a sustained and controllable manner [29].

Magnetic iron oxide (maghemite, $\gamma-\mathrm{Fe}_{2} \mathrm{O}_{3}$ ) nanoparticles are particularly promising due to their high surface area to volume ratio, magnetic properties, biocompatibility, relative non-toxicity, and biodegradability. The use of iron oxide magnetic nanoparticles for various biomedical applications, e.g., hyperthermia, diagnosis, cell-labeling and sorting, DNA separation, MRI contrast agents and drug delivery, have already been demonstrated [30-35].

In this study, we present a novel approach for specific inhibition of microglial cells in rTg4510 tau-transgenic mice by using fibrin $\gamma^{377-395}$ peptide-conjugated $\gamma-\mathrm{Fe}_{2} \mathrm{O}_{3}$ nanoparticles of $21 \pm 3.5 \mathrm{~nm}$ diameter. The stabilization of the peptide by its conjugation to these nanoparticles significantly decreased the number of the microglial cells compared to the same concentration of the free peptide. Furthermore, the specific inhibition of microglial cells, attained using the $\gamma^{377-395}$ peptide-conjugated $\gamma-\mathrm{Fe}_{2} \mathrm{O}_{3}$ nanoparticles, was found to have a dual effect on tau pathology depending on the age of the mice used in the study.

\section{Results}

Specific inhibition of microglial cells using fibrin $\gamma^{377-395}$ peptide-conjugated $\mathrm{\gamma}-\mathrm{Fe}_{2} \mathrm{O}_{3}$ nanoparticles The fibrin derived $\gamma^{377-395}$ peptide has been shown to specifically inhibit microglial activity in vivo [28] and was therefore chosen to facilitate the specific inhibition 
of microglial activity. This peptide, however, possesses a short half-life when administered in saline solution and needs to be administered constantly as a result. To counteract this issue, we have conjugated the peptide to $\gamma-\mathrm{Fe}_{2} \mathrm{O}_{3}$ nanoparticles. The transmission electron microscope (TEM) image of the fibrin $\gamma^{377-395}$ peptideconjugated $\gamma-\mathrm{Fe}_{2} \mathrm{O}_{3}$ nanoparticles shown in Figure 1 demonstrates that these nanoparticles are stable against agglomeration and possess a diameter of $21 \pm 3.5 \mathrm{~nm}$. These nanoparticles have been shown to enhance efficacy of delivery of bioactive material and to provide protection against biodegradation [36]. Fibrin $\gamma^{377-395}$ peptide, once conjugated to the nanoparticles, is retained in the site of injection and does not disperse by diffusion. This was confirmed 30 days post intracranial injection, using potassium ferrocyanide staining, which gave a positive staining with brains treated with the conjugated peptide, whereas no positive staining was seen in brain hemispheres injected with saline or free fibrin $\gamma^{377-395}$ peptide (Figure 2).

To determine the effect of fibrin $\gamma^{377-395}$ peptide on activation of microglial cells, we measured the average numbers of activated microglial cells per area in animals injected with saline versus fibrin $\gamma^{377-395}$ peptideconjugated $\gamma-\mathrm{Fe}_{2} \mathrm{O}_{3}$ nanoparticles, as well as free fibrin $\gamma^{377-395}$ peptide. We were unable to determine the specificity of fibrin $\gamma^{377-395}$ peptide-conjugated $\gamma-\mathrm{Fe}_{2} \mathrm{O}_{3}$ nanoparticles to the microglia. Figure 3 shows examples of activated microglia cells using IB4, a lectin which stains activated microglia. The data were analyzed with a 2-way

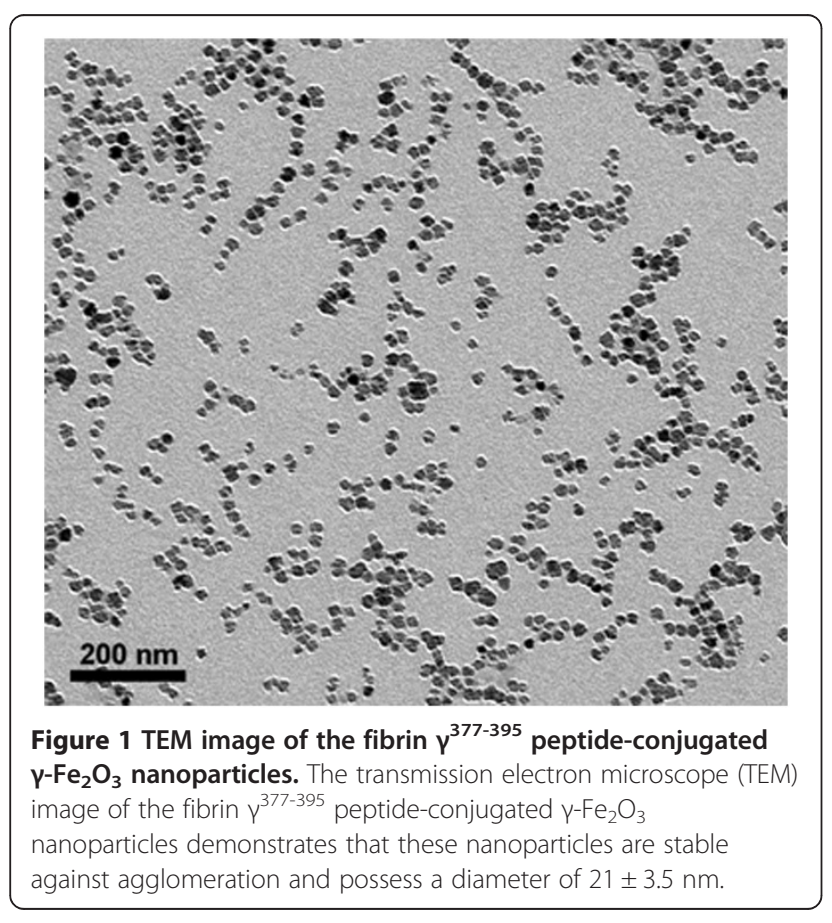

analysis of variance (ANOVA). The fibrin $\gamma^{377-395}$ peptide, when conjugated to the nanoparticles, significantly reduced the number of activated microglia (white arrows) in the site of injection compared to saline (Figure 3, top 2 rows), ( $\mathrm{F}=$ 41.01; (degrees of freedom $(\mathrm{df})=1,274 ; \mathrm{p} \leq 0.05)$. An effect of age was also found ( $\mathrm{F}=74.89 ; \mathrm{df}=1,274 ; \mathrm{p} \leq 0.05)$. In addition, we also found an interaction effect between age and treatment $(\mathrm{F}=4.25 ; \mathrm{df}=1,274 ; \mathrm{p} \leq 0.05)$. These results are summarized in the graphs in Figure 4A. Whereas in both the saline-injected and fibrin $\gamma^{377-395}$ peptide-injected animals, the number of activated microglia increased with age, the rate of increase was reduced in the fibrin $\gamma^{377-395}$ peptide-injected animals, indicating that the conjugated fibrin $\gamma^{377-395}$ peptides reduces the rate of activation of microglial cells. The $\gamma-\mathrm{Fe}_{2} \mathrm{O}_{3}$ nanoparticles have been shown to be an effective mechanism of delivery for peptides in the mammalian brain $[37,38]$. The nanoparticles alone showed no effects, and no neurotoxicity effects of the nanoparticles were observed [36-41]. In addition to staining for activated microglia exclusively, we also stained sections with ionized calcium-binding adapter molecule-1 (Iba-1) a marker for all microglia. The results of this are shown in Figure 3I and 3J, where it is seen that the percentage of amoeboid cells is higher in the hemisphere injected with fibrin $\gamma^{377-395}$ peptide.

The results for injection of the unconjugated peptide revealed a different pattern: In contrast to the conjugated peptide, while the number of activated microglia increased with age, no significant changes were found between the saline and unconjugated peptide-injected conditions (Figure 3, bottom rows). These results are summarized in Figure 4B. While a significant difference was found for age $(\mathrm{F}=6.56$; $\mathrm{df}=1,54 ; \mathrm{p} \leq 0.05)$, no significant differences in the number of activated microglial cells when compared with saline controls $(\mathrm{F}=0.002$; $\mathrm{df}=1,54$; NS; No significant interaction was found between age and treatment: $\mathrm{F}=3.89$, $\mathrm{df}=1,54$; NS). We interpret these results to mean that the unconjugated peptide was ineffective at reducing the rate of activation of microglial cells.

\section{Effects of microglial inhibition on hypersphosphorylated tau and NFTs}

After establishing a practical method of delivery for the inactivation of microglia in the transgenic mice model, we sought to determine whether microglial inhibition affected the accumulation of hyperphosphorylated tau in neocortical neurons. After injecting the fibrin $\gamma^{377-395}$ peptide-conjugated $\gamma-\mathrm{Fe}_{2} \mathrm{O}_{3}$ nanoparticles, the average hyperphosphorylated tau per area surrounding the site of injection was quantified using AT8 antibody staining (Figure 5). Overall, no significant differences were found in the number of cells containing hyperphosphorylated tau (white arrows) in the fibrin-injected brain areas 

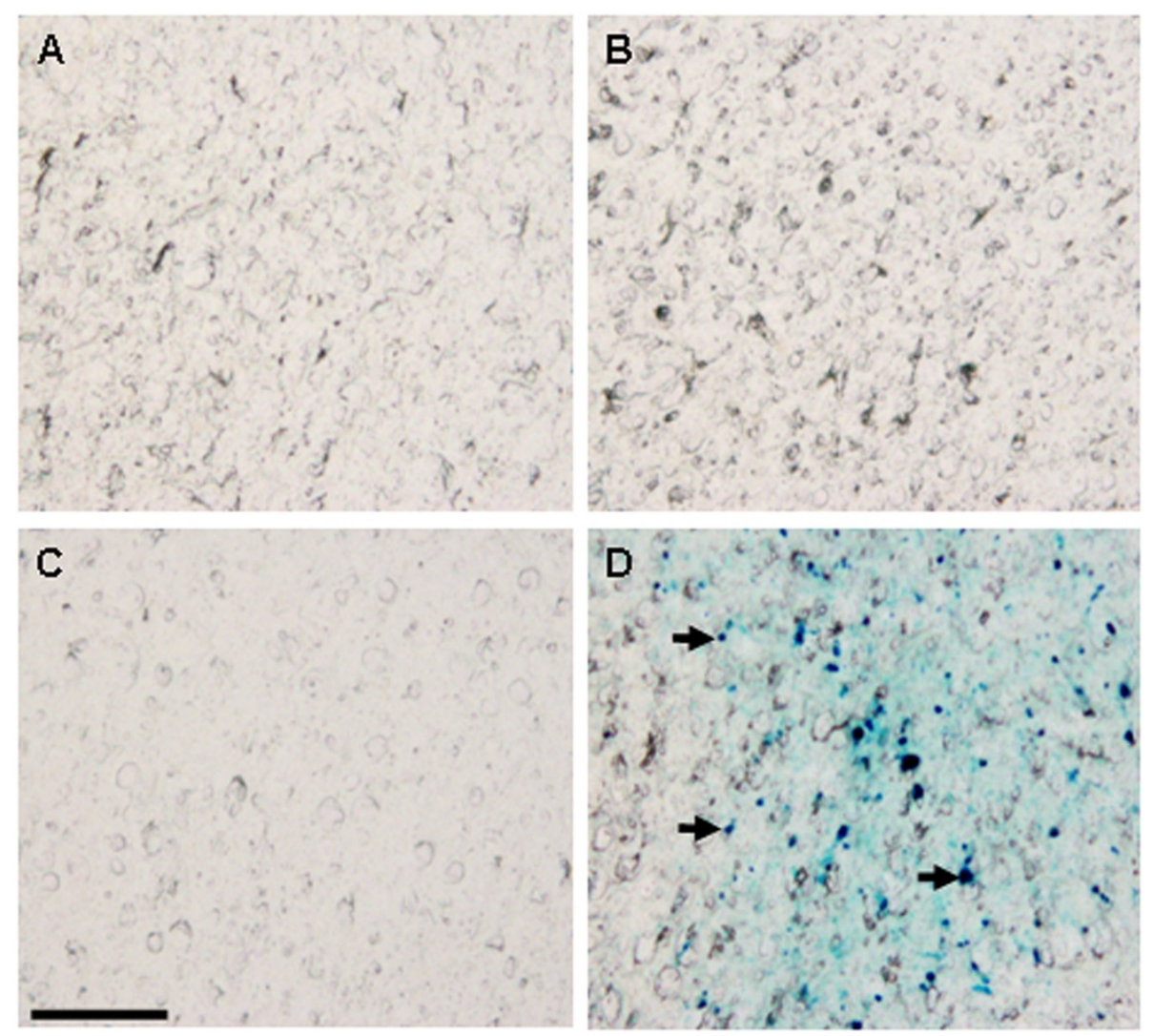

Figure 2 Localization of the fibrin $\gamma^{377-395}$ peptide-conjugated $\gamma-\mathrm{Fe}_{2} \mathrm{O}_{3}$ nanoparticles in the frontal cortex. The $\gamma$ - $\mathrm{Fe}_{2} \mathrm{O}_{3}$ nanoparticles were stained with potassium ferocyanide (blue). No staining was seen in the hemisphere injected with saline (A, C) and free fibrin $\gamma^{377-395}$ peptide (B). Positive staining (D) (arrows) indicates the presence of the nanoparticles. Scale bar: $50 \mu \mathrm{m}$.

when compared with those in saline-injected control hemispheres $(\mathrm{F}=0.05 ; \mathrm{df}=1,289 ; \mathrm{NS})$. A significant difference was found for age $(F=4.22 ; d f=1,289 ; p \leq 0.05)$. A significant interaction effect was found between age and treatment: $(\mathrm{F}=29.5 ; \mathrm{df}=1,289 ; \mathrm{p} \leq 0.05)$, revealing an opposing effect between the "young" and "old" mice following microglial inhibition on the accumulation of hyperphosphorylated tau in cortical neurons. Compared to controls, at age 3.5 months, an increase in the number of cells containing hyperphosphorylated tau was found following microglial inhibition, whereas at age 6 months a decrease in the number of cells containing hyperphosphorylated tau was observed. The results are summarized in the graph in Figure 5. These results suggest that the involvement of microglia in the development of hyperphosphorylated tau is age-dependent or alternatively, dependent on the stage of pathological tau accumulation.

We then tested the effects of microglial inhibition on the number of tangle-containing neurons. The effect of the fibrin $\gamma^{377-395}$ peptide-conjugated $\gamma-\mathrm{Fe}_{2} \mathrm{O}_{3}$ nanoparticles on tangle formation in the frontal cortex is shown in Figure 6. The results are similar to those for the hyperphosphorylated tau. A significant increase is found in the number of tangle-containing neurons (white arrows) with age $(\mathrm{F}=860 ; \mathrm{df}=1,366 ; \mathrm{p} \leq 0.05)$. The effect of microglial inhibition is significant overall $(\mathrm{F}=88.96 ; \mathrm{df}=1,366 ; \mathrm{p} \leq 0.05)$. Again, a significant interaction between age and treatment was found: $(F=136$; $\mathrm{df}=1,366 ; \mathrm{p} \leq 0.05)$. Post hoc comparisons revealed that the differences in tangle-containing neurons between control and treated animals at 3.5 months were non significant, which is not surprising given the very low number of tangles occurring in neocortex at this age in the model. The significant reduction in tangle-containing neurons between control and treated animals occurred only at the age at which significant tangle aggregation occurs in this model. The results are summarized in the graph in Figure 6.

Taken together, these results reveal that microglial inhibition reduces both hyperphosphorylated tau-containing neurons and tangle-containing neurons in older mice. However, hyperphosphorylated tau-containing neurons are increased in younger mice, indicating that the effects of microglial inhibition depend on the stage of the pathological accumulation of tau. 


\section{Saline}
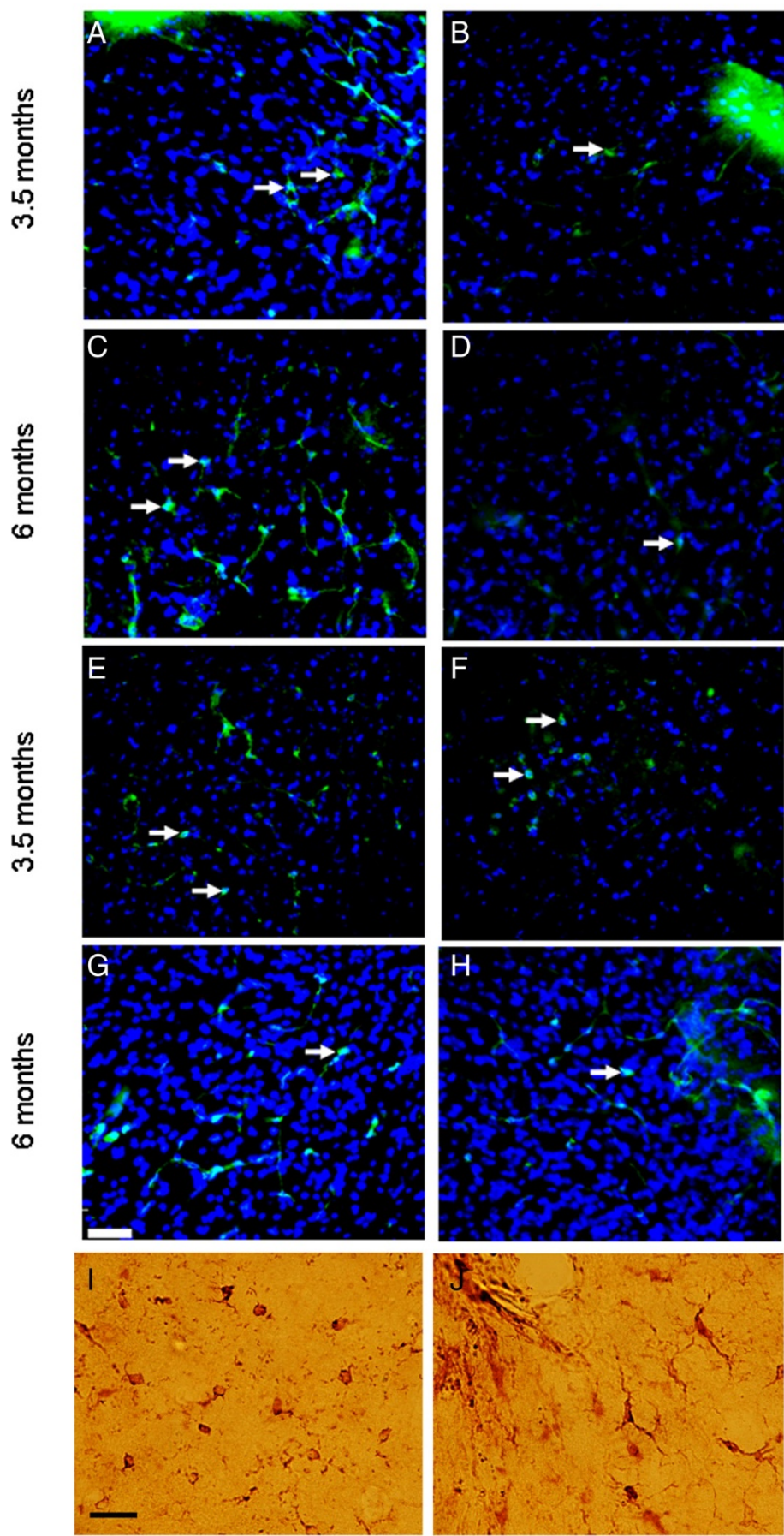

Figure 3 Fibrin $\gamma^{377-395}$ peptide-conjugated $\gamma-\mathrm{Fe}_{2} \mathrm{O}_{3}$ nanoparticles decreased the number of activated microglia. $\mathrm{rTg} 4510$ mice at ages $3.5(\mathbf{A}, \mathbf{B}, \mathbf{E}, \mathbf{F})$ and 6 months $(\mathbf{C}, \mathbf{D}, \mathbf{G}, \mathbf{H})$ were injected given a single intracranial injection unilaterally with saline (left column) or fibrin $\gamma^{377-395}$ peptide-conjugated $\gamma-\mathrm{Fe}_{2} \mathrm{O}_{3}$ nanoparticles $(\mathbf{B}, \mathbf{D})$ or free fibrin $\gamma^{377-395}$ peptide $(\mathbf{F}, \mathbf{H})$ and were sacrificed after 30 days. Activated microglial cells were stained with the lectin IB4 (white arrows). DAPI was used for nuclear staining. Statistical analysis (see Figure 3) revealed a significant reduction in the number of activated microglia following injection with fibrin $\gamma^{377-395}$ peptide-conjugated $\gamma-\mathrm{Fe}_{2} \mathrm{O}_{3}$ nanoparticles (compare $\mathbf{B}$ and D with $\mathbf{A}$ and $\mathbf{C}$ ). Scale bar: 50 mm. I, J; lba-1 staining demonstrates resting and activated microglia. I: saline injection; J: following injection with fibrin $\gamma^{377-395}$ peptide-conjugated $\gamma-\mathrm{Fe}_{2} \mathrm{O}_{3}$ nanoparticles. The differences in shape of the microglia are clearly seen. Scale bar: $25 \mu \mathrm{m}$. 

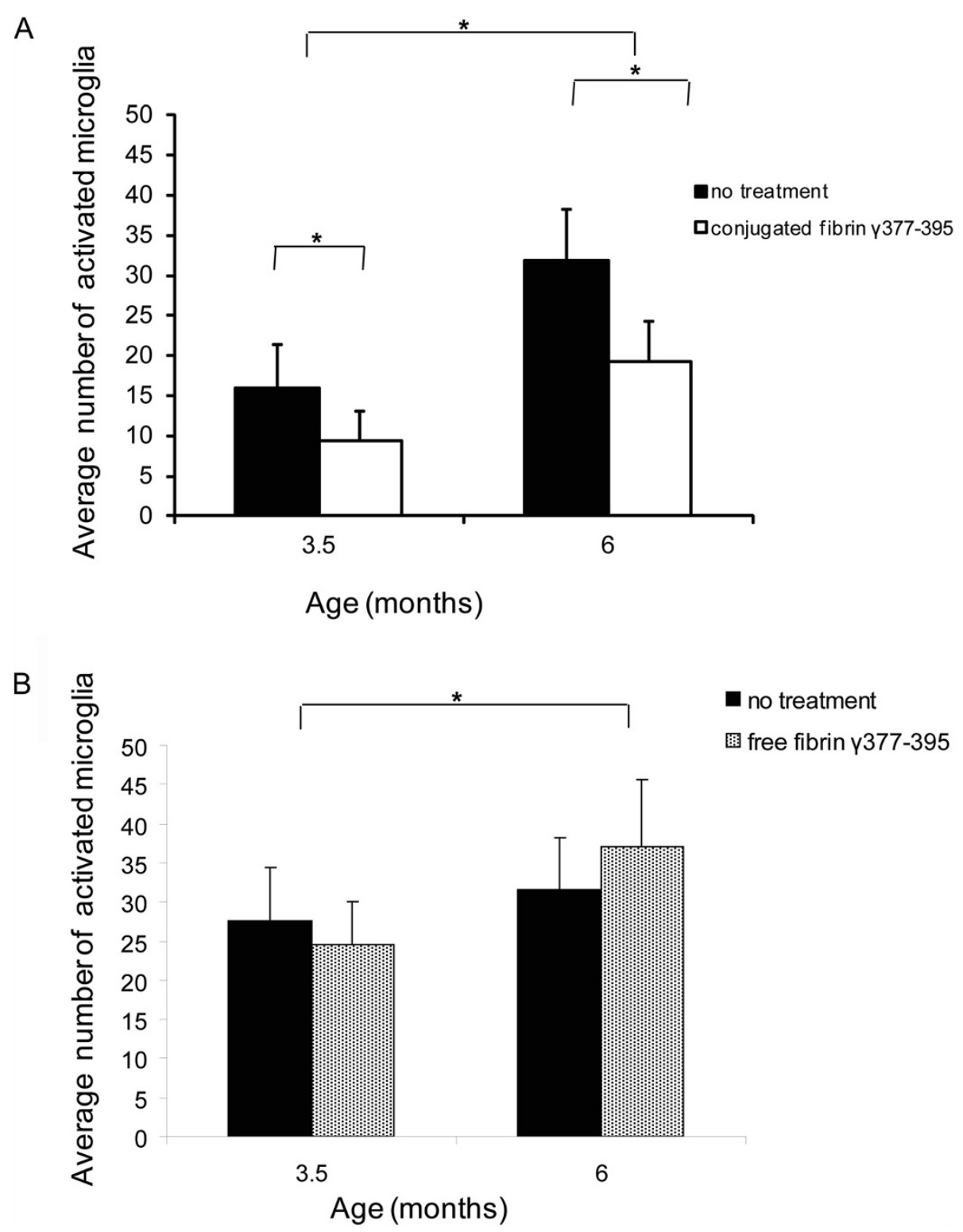

Figure 4 The effect of fibrin $\gamma^{377-395}$ peptide-conjugated $\gamma-\mathrm{Fe}_{2} \mathrm{O}_{3}$ nanoparticles on the number of activated microglia. Statistical analysis was performed using 2-way ANOVA followed by Tukey multiple comparison test. Area count of the stained microglia for IB4 showed a significant decrease in the number of activated microglia at both ages when fibrin $\gamma^{377-395}$ conjugated to nanoparticles was injected compared to saline (A) (at age 3.5 months: $n=5$ mice, 171 areas; at age 6 months: $n=6,108$ areas). Although there was a significant effect for age, no significant differences were found between free fibrin $\gamma^{377-395}$ and saline injections (B) (at age 3.5 months: $n=2$ mice, 20 areas; at age 6 months: $n=3$, 38 areas).

\section{Discussion}

The role of microglia cells in tau pathology is still an open question, and the literature is filled with seemingly contradictive findings on this subject. Previous studies $[21,42]$ have shown that dystrophic rather than activated microglial cells are associated with tau pathology. On the other hand, other studies described that chronic inflammation, caused by a high level of microglial activation, may exacerbate neurodegeneration [26,43]. For example, Yoshiyama et al. [24] have recently shown that administering immunosuppressors reduced tau pathology when mice were treated at an early age for a period of over 8 months.

In light of these contrasting findings we decided to specifically inhibit the activation of microglia cells to rule out systemic factors arising from immunosuppressor treatments. The inhibition was facilitated using fibrin $\gamma^{377-395}$ peptide-conjugated $\gamma-\mathrm{Fe}_{2} \mathrm{O}_{3}$ nanoparticles, which significantly decreased the number of activated microglial cells as compared to the administration of the free peptide in both 


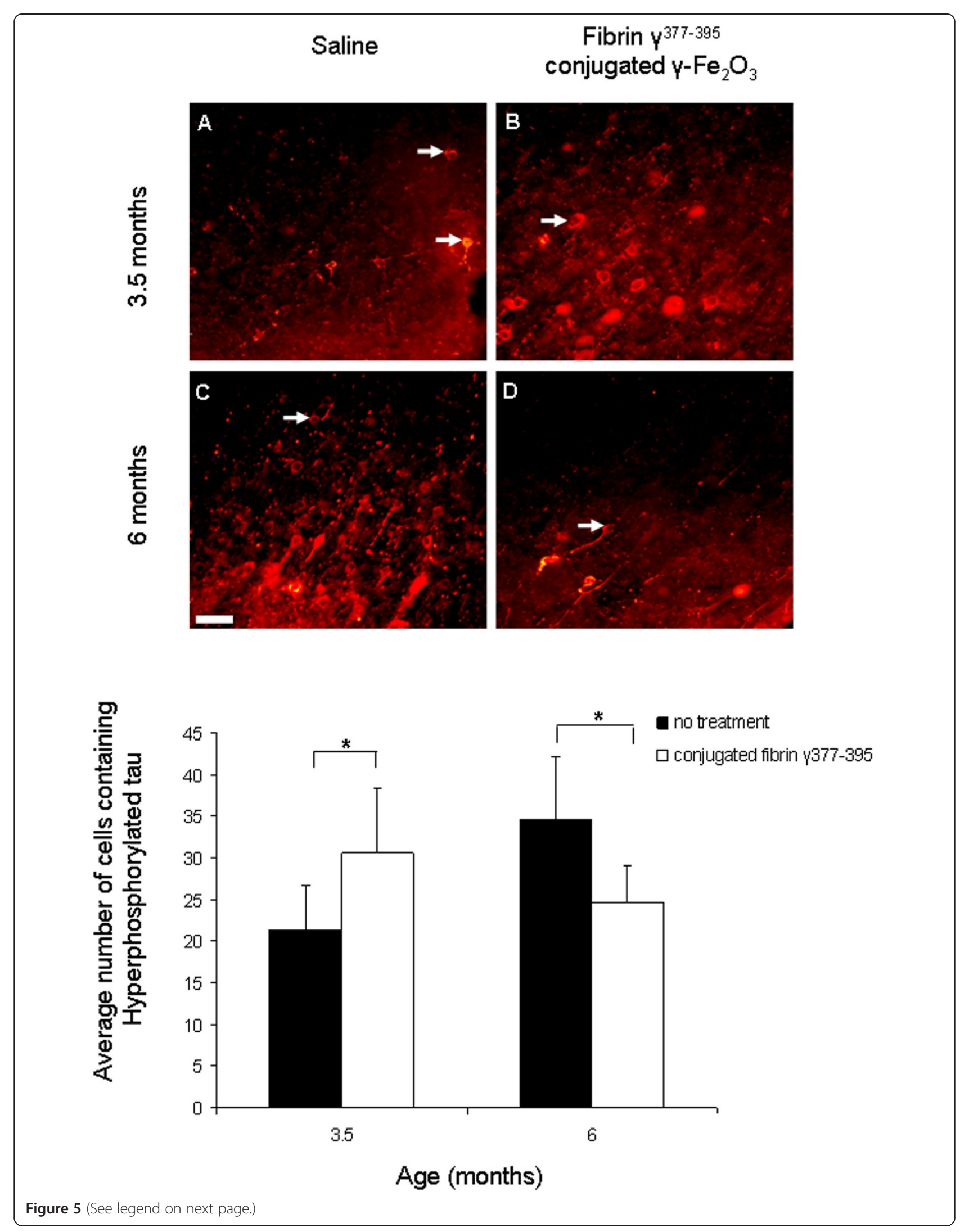


(See figure on previous page.)

Figure $\mathbf{5}$ The effect of microglial inhibition on hyperphosphorylated tau is age dependent. Staining of hyperphosphorylated tau by AT8 revealed significant differences in neurons containing hyperphosphorylated tau. At age 3.5 months injecting the conjugated fibrin $\gamma^{377-395}$ peptide (B) led to an increase in the number of cells containing hyperphosphorylated tau compared with control (A), $(\mathbf{n}=5$ mice, 160 areas). In contrast, at age 6 months, a decrease in the number of hyperphosphorylated tau was observed when comparing the conjugated fibrin $\gamma^{377-395}$ peptide (D) with control (C), $(n=6$ mice, 133 areas). Scale bar: $50 \mu \mathrm{m}$.

age groups examined. This observation was enabled by conjugating of fibrin $\gamma^{377-395}$ peptide to the $\gamma-\mathrm{Fe}_{2} \mathrm{O}_{3}$ nanoparticles, which may have increased the stability of the peptide against proteolytic enzymes present in the body, thus prolonging its activity, compared to that of the free peptide. A similar stabilization effect was reported previously for thrombin [39], glial-cell derived neurotrophic factor [40], bFGF [36], TRAIL [37], factor VIIa [41], and methotrexate [38] conjugated to $\gamma-\mathrm{Fe}_{2} \mathrm{O}_{3}$ nanoparticles.

Our results indicate that the stage of pathology may affect microglial function in relation to the disease process, revealed by the interaction between age and treatment for hyperphosphorylated tau, where an inverse relationship between the number of hyperphosphorylated tau and age of treated mice was reported. In "young" mice an increase in the number of cells containing hypersphosphorylated tau was found, whereas in "old" mice a significant decrease in hyperphosphorylated tau containing neurons was observed. These findings suggest that the microglial cells possess both a beneficial and a harmful role in the pathology of tau depending on the stage of the pathology. We postulate that this effect is a result of two different stages of the pathology: the early stage, when the microglial cells attempt to remove cellular debris before further damage can occur [44] and when they release neurotrophic factors such as NGF, NT-3 and BDNF which have been demonstrate to be neuroprotective [23]; and the late stage of the pathology, when the microglia cells are over activated and excessive levels of pro-inflammatory cytokines are released [45]. The cytokines secreted mainly by activated microglia, namely, interleukine-1 (IL-1), TNF- $\alpha$, and interleukin-6 (IL-6), could affect the normal behavior of neurons and exacerbate tau pathology [46]. Several studies have described that IL-1 $[43,47]$ and IL-6 [46] can induce phosphorylation of tau in neuronal cells, further strengthening this suggestion.

In "young" mice, our study found no differences in NFTs count between mice treated with the fibrin $\gamma^{377-395}$ peptide-conjugated $\gamma-\mathrm{Fe}_{2} \mathrm{O}_{3}$ nanoparticles and the control, whereas in "old" mice a significant reduction in the number of cells containing NFTs was observed. This significant finding is in accordance with a pre-vious study [48] which described that tau is first hypersphosphorylated and then aggregated into NFTs at a later stage, rather than hyperphosphorylated tau accumulation and tangle aggregation occurring in separate populations of cells.

\section{Conclusions}

This study has shown that microglial cells posses a complex relationship with neuropathology. Our work demonstrates that microglial cells can be an effective and perhaps necessary target for therapeutic strategies. Similar evidence has been found in mouse models of amyloid- $\beta$ pathology $[49,50]$. Depending on the stage of the disease, it may be necessary to use a differential approach to microglial activation: increasing activation at early stages and reducing activation at later stages. This has important implications for immunotherapeutic approaches to many neurodegenerative diseases in addition to tauopathies.

This study has also shown the efficacy of $\gamma-\mathrm{Fe}_{2} \mathrm{O}_{3}$ nanoparticles in the stable delivery of fibrin $\gamma^{377-395}$ peptide to nervous tissue in vivo. This method can be used for the study of delivery of a number of substances to the brain, as well as monitoring their presence over time. In addition to use as a tool for experimental drug delivery, it may also be possible to use $\gamma-\mathrm{Fe}_{2} \mathrm{O}_{3}$ nanoparticles as a therapeutic approach for controlled release of substances in the central nervous system.

\section{Materials and methods}

\section{Synthesis of bioactive $\mathrm{\gamma}-\mathrm{Fe}_{2} \mathrm{O}_{3}$ nanoparticles}

The following analytical-grade chemicals were purchased from commercial sources and used without further purification: ferrous chloride tetrahydrate, hydrochloric acid (1 M), sodium hydroxide (1 M standard solution), sodium chloride, sodium nitrite, gelatin from porcine skin, divinyl sulfone (DVS), triethylamine (TEA) from Sigma (Israel); fibrinogen-derived $\gamma^{377-395}$ peptide from AnaSpec (Israel); Bicarbonate buffer (BB, 0.1 M, pH 8.4) and phosphatebuffered saline (PBS free of $\mathrm{Ca}^{+2}$ and $\mathrm{Mg}^{+2}, 0.1 \mathrm{M}, \mathrm{pH} 7.4$ ) from Biological-Industries (Israel); midi MACS magnetic columns from Miltenyi Biotec GmbH (Germany). Water was purified by passing deionized water through an Elgastat Spectrum reverse osmosis system (Elga, High Wycombe, UK).

$\gamma-\mathrm{Fe}_{2} \mathrm{O}_{3}$ and DVS-derivatized $\gamma-\mathrm{Fe}_{2} \mathrm{O}_{3}$ nanoparticles were prepared according to our previous publications [36]. The covalent conjugation of fibrin $\gamma^{377-395}$ peptide to the $\gamma-\mathrm{Fe}_{2} \mathrm{O}_{3}$ nanoparticles was accomplished via the Michael addition reaction [36]. Briefly, $50 \mu \mathrm{l}$ of a fibrin $\gamma^{377-395}$ peptide PBS solution (1 mg/ml, pH 7.4) were added to $143 \mu \mathrm{l}$ of the DVS-derivatized $\gamma-\mathrm{Fe}_{2} \mathrm{O}_{3}$ nanoparticles dispersed in $\mathrm{BB}(3.5 \mathrm{mg} / \mathrm{ml}, \mathrm{pH} 8.4)$ at a 

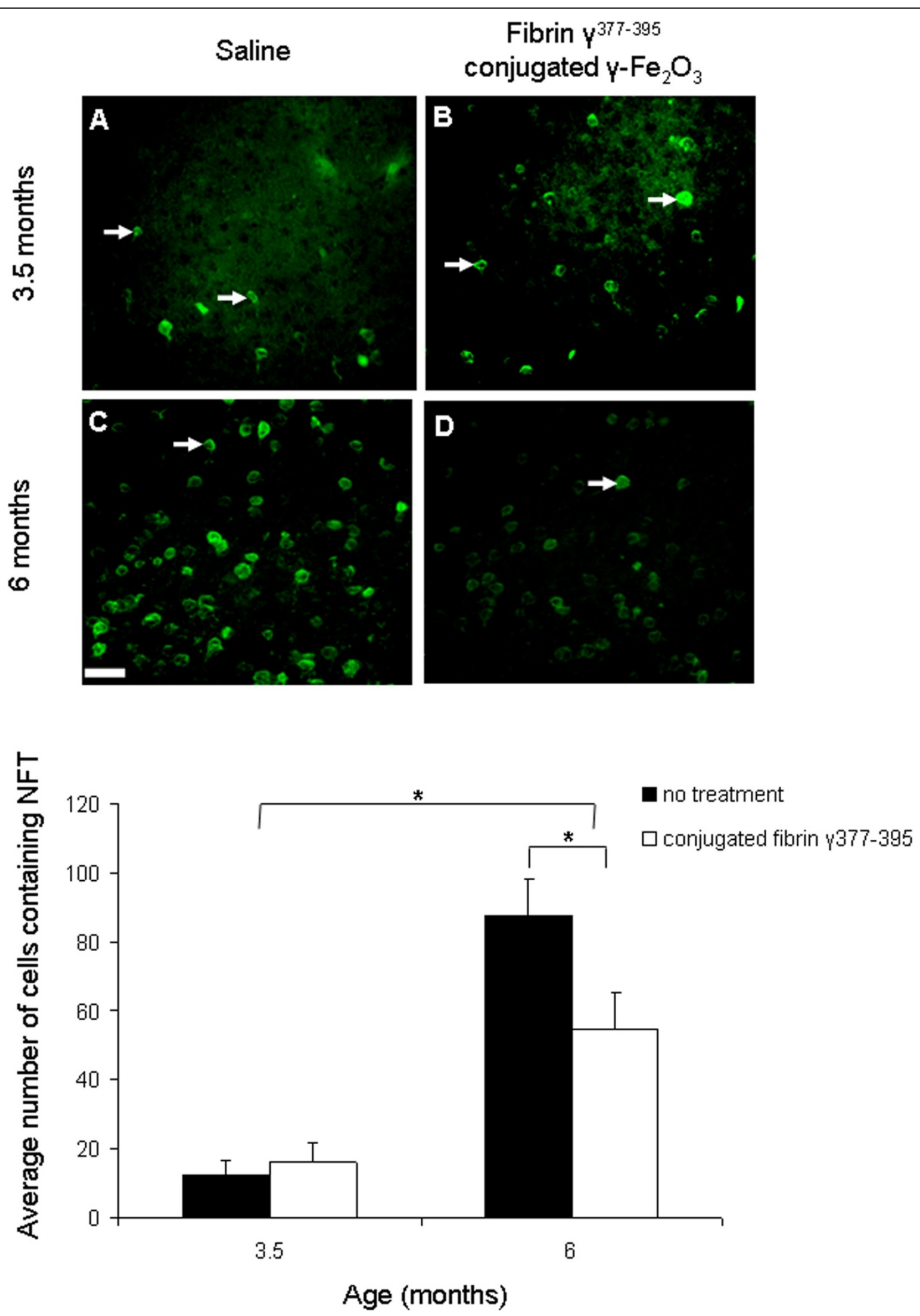

Figure 6 (See legend on next page.) 
(See figure on previous page.)

Figure 6 The effect of microglial inhibition on NFTs. Staining of NFTs by Thioflavin-S revealed a reduction in neurons containing NFT in mice

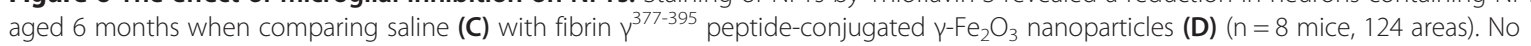
differences in NFTs were found in mice aged 3.5 months when comparing saline (A) with the treatment hemisphere $\mathbf{( B )}(\mathrm{n}=4$ mice, 246 areas). Scale bar: $50 \mu \mathrm{m}$.

[nanoparticles] $/\left[\gamma^{377-395}\right]$ weight ratio of 10 . The reaction mixture was then shaken at room temperature for $18 \mathrm{~h}$. Blocking of the residual double bonds was then accomplished by adding $1 \%$ glycine (w/v) and then shaking for an additional hour. The obtained fibrin $\gamma^{377-395}$ peptideconjugated $\gamma-\mathrm{Fe}_{2} \mathrm{O}_{3}$ nanoparticles were than washed from non-magnetic waste with PBS using the high gradient magnetic field (HGMF) technique [34]. The concentration of the $\gamma^{377-395}$ peptide conjugated to the nanoparticles was determined by measuring the unbound peptide using the Bradford assay and subtracting it from the initial concentration [51].

\section{Animal model}

rTg4510 mice were used in this study. Santa Cruz et al. [52] created these transgenic mice using a CaMII alpha promoter driven by a tetracycline operator to focus human mutant P301L tau over-expression in the forebrain (hippocampus and higher cortical layers) of the mice.

Nine rTg4510 mice aged 3.5 months ("young") and 7 rTg4510 aged 6 months ("old") were used in this study. Mice weight, on average, was $25 \mathrm{~g}$. All procedures were performed in accordance with the NIH Guide for the Care and Use of Laboratory Animals, and with the BarIlan University guidelines for the use and care of laboratory animals in research, approved and supervised by the Institutional Animal Care and Use Committee.

\section{Intracranial injections}

3.5 and 6 month old rTg4510 mice were injected intracranially with the fibrin $\gamma^{377-395}$ peptide-conjugated $\gamma$-Fe ${ }_{2} \mathrm{O}_{3}$ nanoparticles and free fibrin $\gamma^{377-395}$ peptide (1:3 weight ratio). Briefly, mice were anaesthetized before surgery with a ketamine:xylazine at 150 and $12 \mathrm{mg} / \mathrm{kg}$, respectively [53]. The animals were then placed into a stereotaxic apparatus with a heating pad to maintain body temperature. Stereotaxic coordinates were bregma + $1.5 \mathrm{~mm}$ anterior-posterior, $1.5 \mathrm{~mm}$ lateral and $1.8 \mathrm{~mm}$ vertical for frontal cortex. Subsequently, $10 \mu \mathrm{L}$ of the fibrin $\gamma^{377-395}$ peptide-conjugated $\gamma$ - $\mathrm{Fe}_{2} \mathrm{O}_{3}$ nanoparticles dispersed in PBS $\left(2 \mathrm{mg} / \mathrm{ml}, 10\right.$ ug bound fibrin $\gamma^{377-395}$ per injection) and free fibrin $\gamma^{377-395}$ peptide dissolved in a PBS solution $(3 \mathrm{mg} / \mathrm{ml})$, were intracranially injected in the right and left hemispheres, respectively. The injection holes were then filled with bone wax. The mice were stitched and then returned to their cages. All mice used in our experiments were then sacrificed 30 days post injection via an intracardial perfusion described in the next section.

\section{Tissue preparation}

The animals were given a lethal dose of thiopental sodium solution and were perfused intracardially with isotonic PBS ( $\mathrm{pH} 7.3$ ) followed by $4 \%$ paraformaldehyde solution in $0.1 \mathrm{M}$ PBS. Once the perfusions were complete, the brains were rapidly removed from the skulls and were placed in a $4 \%$ paraformaldehyde solution for post-fixation of at least $24 \mathrm{~h}$ at $4^{\circ} \mathrm{C}$. After $24 \mathrm{~h}$, the brains were transferred to a $30 \%$ sucrose solution for two days. The brains were then frozen in dry ice and placed in $-80^{\circ} \mathrm{C}$ over night. Before sectioning the brains with a cryostat, the brains were covered using an optimal cutting temperature (OCT) solution and were placed in $-20^{\circ} \mathrm{C}$. Once the OCT solidified, the brains were placed in the cryostat with the frontal side up. Tissue samples were selected from areas of cortex adjacent to the injection sites. The brains were sliced to $25 \mu \mathrm{m}$ coronal sections. Each sample consisted of 5 slices. Controls were the contralateral areas. Sampling within the slices was performed at 3 sites, each $400 \times 340 \mu \mathrm{m}$. The brain sections were then individually picked up using a paint brush and were transferred to a well filled with $0.1 \mathrm{M}$ PBS. Slices were then either stained immediately following the appropriate protocol or stored in a cryoprotectant solution at $-20^{\circ} \mathrm{C}$ until further use.

\section{Staining methods \\ Lectin staining}

The slices were first introduced into a PBS solution in order to remove the OCT from the tissue. The slices were treated with FITC-conjugated Bandeiraea simplicifolia isolectin B4 (IB-4; 1:50; Sigma-Aldrich) for $1 \mathrm{~h}$, and then were washed three times for 5 min each in PBS. The slices were then mounted on slides and stored in the dark to air-dry. A drop of DAPI (1:2000; SigmaAldrich) solution was added to sections after drying using a Pasteur pipette for $1 \mathrm{~min}$ and washed twice for 1 min each in PBS. The slides were then sealed using a cover slip.

\section{Iron staining}

The slices were mounted on slides and placed in $2 \%$ potassium ferrocyanide solution with $2 \% \mathrm{HCl}$ solution for 30 min. Afterwards, the slides were washed three times in distilled water and sealed with a cover slip. 


\section{Immunohistochemistry}

The slices were first introduced into a PBS solution in order to remove the OCT from the tissue. The slices were incubated in $0.5 \%$ Triton for $20 \mathrm{~min}$ and then washed three times for $5 \mathrm{~min}$ each in PBS. The slices were then incubated in a blocking solution (NGS, $5 \%$ in PBS; from Jackson Immuno Research) for $1 \mathrm{~h}$. After the blocking stage, slices were treated with Anti-HumanPHF-Tau Monoclonal Antibody (AT8; 1:1000 in normal goat serum; Thermo Scientific) and then left overnight at $4^{\circ} \mathrm{C}$. Following incubation, the slices were washed three times for $5 \mathrm{~min}$ each in PBS. The slices were treated with Cy3 donkey anti-mouse (Cy3 1:500, Jackson Immuno Research). After $1 \mathrm{~h}$, the slices were washed three times in PBS. The slices were then mounted on slides, stored in the dark to air-dry and then sealed using a cover slip. If NFTs staining was performed as well, a drop of $0.05 \%$ Thio-S solution (Sigma-Aldrich) was added to sections after drying using a Pasteur pipette. The sections were then incubated for $8 \mathrm{~min}$ in the dark, followed by two washes for $10 \mathrm{sec}$ in $80 \%$ ethanol solution and one wash in distilled water. The slides were then stored in the dark to air-dry and sealed using a cover slip.

To study microglia morphology, Iba-1 staining was performed. The endogenous peroxidase was blocked by $10 \% \mathrm{H} 2 \mathrm{O} 2,0.01 \%$ Triton X-100 in PBS, and 3\% Methanol. After 30 minutes blocking was performed by $20 \%$ NGS for $1 \mathrm{~h}$. Slices were then incubated overnight in rabbit polyclonal anti-IBA1 antibody (1:250; Wako Chemicals) with $2 \%$ NGS. Following incubation the sections were treated with a secondary antibody, Anti rabbit IgG Peroxidase (1:200; Santa Cruz) for $1 \mathrm{~h}$ followed by incubation with $\mathrm{ABC}$ solution (Vector) for 30 minutes. The peroxidase labeling was visualized by incubation with commercial DAB Substrate Kit (Vector) for a few minutes. The reaction was stopped by placing the slices in PBS. Slices were then mounted, dehydrated, and cover-slipped.

\section{Statistical analysis}

Two to three different areas surrounding the site of injection from five slices from each mouse were defined for the analysis of activated microglial cells and cells containing hypersphosphorylated tau and NFTs. Statistical analysis was performed using 2-way-ANOVAs followed by Tukey multiple comparison tests. A significance level of $p \leq 0.05$ was set for all statistical tests.

\section{Competing interests}

The authors declare that they have no competing interests.

\section{Authors' contributions}

MG participated in the design of the study, conducted the experiments, analyzed the data, and wrote the manuscript. HS participated in the design of the study, synthesized the bioactive nanoparticles and helped to draft the manuscript. NMC conducted the experiments. SM and EAS conceived the idea of the project, SM supervised the synthesis of the bioactive nanoparticles, and EAS designed and supervised the biological experiments, analysis and the writing of the manuscript. All authors read and approved the final manuscript. All authors have reviewed the manuscript.

\section{Acknowledgements}

We thank Professor George A. Carlson and Ms. Rose Pitstick, McLaughlin Research Institute, Montana State University, for supplying the breeders for the rTg4510 mouse colony.

\section{Funding}

This work was supported by the Elias, Genevieve and Georgianna Atol Charitable Trust.

\section{Author details}

'Gonda Multidisciplinary Brain Research Center, Bar-llan University, Ramat-Gan 52900, Israel. ${ }^{2}$ Department of Chemistry, Bar-llan Institute of Nanotechnology and Advanced Materials, Ramat-Gan 52900, Israel. ${ }^{3}$ MassGeneral Institute of Neurodegenerative Disease, Massachusetts Genral Hospital and Harvard Medical School, Charlestown, MA 02129, USA.

Received: 21 May 2013 Accepted: 16 September 2013

Published: 23 September 2013

\section{References}

1. Spillantini MG, Goedert M: Tau protein pathology in neurodegenerative diseases. Trends Neurosci 1998, 21:428-433.

2. Weingarten MD, Lockwood AH, Hwo SY, Kirschner MW: A protein factor essential for microtubule assembly. Proc Natl Acad Sci U S A 1975, 72:1858-1862.

3. Drubin D, Kobayashi S, Kirschner M: Association of tau protein with microtubules in living cells. Ann N Y Acad Sci 1986, 466:257-268.

4. Neve RL, Harris P, Kosik KS, Kurnit DM, Donlon TA: Identification of CDNA clones for the human microtubule-associated protein tau and chromosomal localization of the genes for tau and microtubuleassociated protein 2. Brain Res 1986, 387:271-280.

5. Goedert M, Spillantini MG, Jakes R, Rutherford D, Crowther RA: Multiple isoforms of human microtubule-associated protein tau: sequences and localization in neurofibrillary tangles of Alzheimer's disease. Neuron 1989, 3:519-526.

6. Kosik KS: The molecular and cellular pathology of Alzheimer neurofibrillary lesions. J Gerontol 1989, 44:55-58.

7. Arrasate M, Perez M, Avila J: Tau dephosphorylation at tau-1 site correlates with its association to cell membrane. Neurochem Res 2000, 25:43-50.

8. Kawamata T, Taniguchi T, Mukai H, Kitagawa M, Hashimoto T, Maeda K, Ono $Y$, Tanaka C: A protein kinase, PKN, accumulates in Alzheimer neurofibrillary tangles and associated endoplasmic reticulum-derived vesicles and phosphorylates tau protein. J Neurosci 1998, 18:7402-7410.

9. Alvarez A, Toro R, Caceres A, Maccioni RB: Inhibition of tau phosphorylating protein kinase cdk5 prevents beta-amyloid-induced neuronal death. FEBS Lett 1999, 459:421-426.

10. Zhang YJ, Xu YF, Liu YH, Yin J, Wang JZ: Nitric oxide induces tau hyperphosphorylation via glycogen synthase kinase-3beta activation. FEBS Lett 2005, 579:6230-6236.

11. Lee HG, Perry G, Moreira PI, Garrett MR, Liu Q, Zhu X, Takeda A, Nunomura A, Smith MA: Tau phosphorylation in Alzheimer's disease: pathogen or protector? Trends Mol Med 2005, 11:164-169.

12. Spires TL, Orne JD, SantaCruz K, Pitstick R, Carlson GA, Ashe KH, Hyman BT: Region-specific dissociation of neuronal loss and neurofibrillary pathology in a mouse model of tauopathy. Am J Pathol 2006, 168:1598-1607.

13. Kreutzberg GW: Microglia: a sensor for pathological events in the CNS. Trends Neurosci 1996, 19:312-318.

14. Gonzalez-Scarano F, Baltuch G: Microglia as mediators of inflammatory and degenerative diseases. Annu Rev Neurosci 1999, 22:219-240.

15. Thomas WE: Brain macrophages: evaluation of microglia and their functions. Brain Res Brain Res Rev 1992, 17:61-74.

16. Aloisi F: Immune function of microglia. Glia 2001, 36:165-179. 
17. Hanisch UK: Microglia as a source and target of cytokines. Glia 2002, 40:140-155.

18. Cullheim $S$, Thams $S$ : The microglial networks of the brain and their role in neuronal network plasticity after lesion. Brain Res Rev 2007, 55:89-96.

19. Trapp BD, Wujek JR, Criste GA, Jalabi W, Yin X, Kidd GJ, Stohlman S, Ransohoff R: Evidence for synaptic stripping by cortical microglia. Glia 2007, 55:360-368.

20. Neumann H, Kotter MR, Franklin RJ: Debris clearance by microglia: an essential link between degeneration and regeneration. Brain 2009, 132:288-295.

21. Streit WJ, Braak H, Xue QS, Bechmann I: Dystrophic (senescent) rather than activated microglial cells are associated with tau pathology and likely precede neurodegeneration in Alzheimer's disease. Acta Neuropathol 2009, 118:475-485.

22. Li L, Lu J, Tay SS, Moochhala SM, He BP: The function of microglia, either neuroprotection or neurotoxicity, is determined by the equilibrium among factors released from activated microglia in vitro. Brain Res 2007, 1159:8-17.

23. Nakajima K, Honda S, Tohyama Y, Imai Y, Kohsaka S, Kurihara T: Neurotrophin secretion from cultured microglia. J Neurosci Res 2001, 65:322-331.

24. Yoshiyama Y, Higuchi M, Zhang B, Huang SM, Iwata N, Saido TC, Maeda J, Suhara T, Trojanowski JQ, Lee VM: Synapse loss and microglial activation precede tangles in a P301S tauopathy mouse model. Neuron 2007, 53:337-351.

25. Gorlovoy P, Larionov S, Pham TT, Neumann H: Accumulation of tau induced in neurites by microglial proinflammatory mediators. FASEB $J$ 2009, 23:2502-2513.

26. Kitazawa M, Oddo S, Yamasaki TR, Green KN, LaFerla FM: Lipopolysaccharide-induced inflammation exacerbates tau pathology by a cyclin-dependent kinase 5-mediated pathway in a transgenic model of Alzheimer's disease. J Neurosci 2005, 25:8843-8853.

27. Ugarova TP, Solovjov DA, Zhang L, Loukinov DI, Yee VC, Medved LV, Plow EF: Identification of a novel recognition sequence for integrin alphaM beta2 within the gamma-chain of fibrinogen. J Biol Chem 1998, 273:22519-22527.

28. Adams RA, Bauer J, Flick MJ, Sikorski SL, Nuriel T, Lassmann H, Degen JL, Akassoglou K: The fibrin-derived gamma377-395 peptide inhibits microglia activation and suppresses relapsing paralysis in central nervous system autoimmune disease. J Exp Med 2007, 204:571-582.

29. Slomkowski S, Gosecki M: Progress in nanoparticulate systems for peptide, proteins and nucleic acid drug delivery. Curr Pharm Biotechnol 2011, 12:1823-1839.

30. de Vries IJM, Lesterhuis WJ, Barentsz JO, Verdijk P, van Krieken JH, Boerman OC, Oyen WJG, Bonenkamp JJ, Boezeman JB, Adema GJ: Magnetic resonance tracking of dendritic cells in melanoma patients for monitoring of cellular therapy. Nat Biotechnol 2005, 23:1407-1413.

31. Hergt R, Hiergeist R, Hilger I, Kaiser WA, Lapatnikov Y, Margel S, Richter U: Maghemite nanoparticles with very high AC-losses for application in RFmagnetic hyperthermia. J Magn Magn Mater 2004, 270:345-357.

32. Scherer F, Anton M, Schillinger U, Henke J, Bergemann C, Kruger A Gansbacher B, Plank C: Magnetofection: enhancing and targeting gene delivery by magnetic force in vitro and in vivo. Gene Ther 2002, 9:102-109.

33. Rudge SR, Kurtz TL, Vessely CR, Catterall LG, Williamson DL: Preparation, characterization, and performance of magnetic iron-carbon composite microparticles for chemotherapy. Biomaterials 2000, 21:1411-1420.

34. Margel S, Gura S: Nucleation and growth magnetic metal oxide nanoparticles and its use. Israel patent 2006. No. WO9962079.

35. Perlstein B, Ram Z, Daniels D, Ocherashvilli A, Roth Y, Margel S, Mardor Y: Convection-enhanced delivery of maghemite nanoparticles: increased efficacy and MRI monitoring. Neuro Oncol 2008, 10:153-161.

36. Skaat $H_{1}$ Ziv O, Shahar A, Margel S: Enhancement of the growth and differentiation of nasal olfactory mucosa cells by the conjugation of growth factors to functional nanoparticles. Bioconjugate Chem 2011, 22:2600-2610.

37. Margel S, Perlstein B, Brodie C: Polymer nanoparticles coated by magnetic metal oxide and uses thereof. US patent 2009. No. WO 2009/040811.

38. Corem-Salkmon E, Ram Z, Daniels D, Perlstein B, Last D, Salomon S, Tamar $G$, Shneor R, Guez D, Margel S: Convection-enhanced delivery of methotrexate-loaded maghemite nanoparticles. Int J Nanomedicine 2011, 6:1595-1602.
39. Ziv-Polat O, Topaz M, Brosh T, Margel S: Enhancement of incisional wound healing by thrombin conjugated iron oxide nanoparticles. Biomaterials 2010, 31:741-747.

40. Green-Sadan T, Kuttner Y, Lublin-Tennenbaum T, Kinor N, Boguslavsky Y, Margel S, Yadid G: Glial cell line-derived neurotrophic factor-conjugated nanoparticles suppress acquisition of cocaine self-administration in rats. Exp Neurol 2005, 194:97-105.

41. Shafir G, Galperin A, Margel S: Synthesis and characterization of recombinant factor VIla-conjugated magnetic iron oxide nanoparticles for hemophilia treatment. J Biomed Mater Res Part A 2009, 91:1056-1064

42. Streit WJ: Microglia and neuroprotection: implications for Alzheimer's disease. Brain Res Brain Res Rev 2005, 48:234-239.

43. Li Y, Liu L, Barger SW, Griffin WS: Interleukin-1 mediates pathological effects of microglia on tau phosphorylation and on synaptophysin synthesis in cortical neurons through a p38-MAPK pathway. J Neurosci 2003, 23:1605-1611.

44. Rogers J, Strohmeyer R, Kovelowski CJ, Li R: Microglia and inflammatory mechanisms in the clearance of amyloid beta peptide. Glia 2002, 40:260-269.

45. Morales I, Farias G, Maccioni RB: Neuroimmunomodulation in the pathogenesis of Alzheimer's disease. Neuroimmunomodulation 2010, 17:202-204.

46. Quintanilla RA, Orellana DI, Gonzalez-Billault C, Maccioni RB: Interleukin-6 induces Alzheimer-type phosphorylation of tau protein by deregulating the cdk5/p35 pathway. Exp Cell Res 2004, 295:245-257.

47. Mrak RE, Griffin WS: Potential inflammatory biomarkers in Alzheimer's disease. J Alzheimers Dis 2005, 8:369-375.

48. Avila J, Lucas JJ, Perez M, Hernandez F: Role of tau protein in both physiological and pathological conditions. Physiol Rev 2004, 84:361-384.

49. Garcia-Alloza M, Ferrara BJ, Dodwell SA, Hickey GA, Hyman BT, Bacskai BJ: A limited role for microglia in antibody mediated plaque clearance in APP mice. Neurobiol Dis 2007, 28:286-292.

50. Koenigsknecht-Talboo J, Meyer-Luehmann M, Parsadanian M, Garcia-Alloza M, Finn MB, Hyman BT, Bacskai BJ, Holtzman DM: Rapid microglial response around amyloid pathology after systemic anti-Abeta antibody administration in PDAPP mice. J Neurosci 2008, 24:14156-14164.

51. Bradford MM: A rapid and sensitive method for the quantitation of microgram quantities of protein utilizing the principle of protein-dye binding. Anal Biochem 1976, 72:248-254.

52. Santacruz K, Lewis J, Spires T, Paulson J, Kotilinek L, Ingelsson M, Guimaraes A, DeTure M, Ramsden M, McGowan E, Forster C, Yue M, Orne J, Janus C, Mariash A, Kuskowski M, Hyman B, Hutton M, Ashe KH: Tau suppression in a neurodegenerative mouse model improves memory function. Science 2005, 309:476-481.

53. Stern EA, Bacskai BJ, Hickey GA, Attenello FJ, Lombardo JA, Hyman BT: Cortical synaptic integration in vivo is disrupted by amyloid-beta plaques. J Neurosci 2004, 24:4535-4540.

doi:10.1186/1477-3155-11-32

Cite this article as: Glat et al: Age-dependent effects of microglial inhibition in vivo on Alzheimer's disease neuropathology using bioactive-conjugated iron oxide nanoparticles. Journal of Nanobiotechnology 2013 11:32.

\section{Submit your next manuscript to BioMed Central and take full advantage of:}

- Convenient online submission

- Thorough peer review

- No space constraints or color figure charges

- Immediate publication on acceptance

- Inclusion in PubMed, CAS, Scopus and Google Scholar

- Research which is freely available for redistribution 